\title{
Controllable Preparation and Electrochemical Behavior of Nanostructured $\mathrm{Zn}_{2} \mathrm{GeO}_{4}$
}

\author{
Wen-Jiu WANG ${ }^{a}$, Qi-Fan WANG ${ }^{b}$, Shi-Zhao KANG ${ }^{\mathrm{c}, *}$, Xiang-Qing LI ${ }^{\mathrm{d}}$, Li-Xia \\ $\mathrm{QIN}^{\mathrm{e}}$, Jin MU $\mathrm{M}^{\mathrm{f}, *}$
}

School of Chemical and Environmental Engineering, Shanghai Institute of Technology, 100 Haiquan Road, Shanghai 201418, China

a1140175263@qq.com, bvan.q@foxmail.com, ckangsz@sit.edu.cn, dxqli@sit.edu.cn, eIxqin@sit.edu.cn, ${ }^{\mathrm{f}}$ mujin@sit.edu.cn

Keywords: $\mathrm{Zn}_{2} \mathrm{GeO}_{4}$, Nanomaterial, Preparation, Electrochemical behavior.

\begin{abstract}
A series of nanostructured $\mathrm{Zn}_{2} \mathrm{GeO}_{4}$ were prepared in a low temperature solvothermal process and characterized with transmission electron microscopy and $\mathrm{X}$-ray diffraction. Then, the formation mechanism of nanostructured $\mathrm{Zn}_{2} \mathrm{GeO}_{4}$ was discussed. At last, their electrochemical behavior was investigated. The results indicate that the $\mathrm{Zn}_{2} \mathrm{GeO}_{4}$ nanorods can exhibit more excellent electrochemical activity.
\end{abstract}

\section{Introduction}

The application prospect of one-dimensional germanate nanomaterials in the electrochemical sensor [1], photocatalyst [2], and nano electronic devices [3] is very attractive. Thus, they were paid more and more attention. Therein, one-dimensional nanostructured $\mathrm{Zn}_{2} \mathrm{GeO}_{4}$ was especially concerned due to its excellent optical and photocatalytic properties. There were a large number of studies and reports [4,5,6]. However, from the present point of view, the research of $\mathrm{Zn}_{2} \mathrm{GeO}_{4}$ is mainly focused on its application in photocatalysis. Studies on the morphology of $\mathrm{Zn}_{2} \mathrm{GeO}_{4}$ and the relationship between the morphology and properties of $\mathrm{Zn}_{2} \mathrm{GeO}_{4}$ are relatively few. Therefore, it is necessary to carry out research in this area. In addition, it has been reported that the morphology of nanomaterials can be controlled by oleylamine and lactic acid [7,8]. Therefore, we have prepared $\mathrm{Zn}_{2} \mathrm{GeO}_{4}$ using mild hydrothermal method, and the morphology controlled by oleylamine and lactic acid was explored preliminarily. On this basis, we also investigated the electrochemical properties of the nanostructured $\mathrm{Zn}_{2} \mathrm{GeO}_{4}$.

\section{Experimental}

Nanostructured $\mathrm{Zn}_{2} \mathrm{GeO}_{4}$ was prepared in a low temperature solvothermal process. Typically, $\mathrm{GeO}_{2}$ $(0.52 \mathrm{~g})$ and zinc acetate $(2.20 \mathrm{~g})$ were dissolved in deionized water $(30 \mathrm{~mL})$. Then, corresponding crystal modifier was added and stirred for about $1 \mathrm{~h}$. After $\mathrm{pH}$ was adjusted to 8 by $10 \mathrm{~mol} \mathrm{~L}^{-1} \mathrm{NaOH}$ solution, the solution above was transferred into a teflon-lined vessel $(50 \mathrm{~mL})$ and heated to $180{ }^{\circ} \mathrm{C}$ for $12 \mathrm{~h}$. Subsequently, the autoclave was naturally cooled to ambient temperature. The precipitate was collected by filtration and washed with ethanol and water for several times, respectively. Finally, the resulting product was dried at $60^{\circ} \mathrm{C}$ for $2 \mathrm{~h}$.

The electrochemical behavior of the samples was measured using a CHI660E electrochemical system (Shanghai Chenhua Instruments, China) in a conventional three-electrode cell. The GCE coated with the nanostructured $\mathrm{Zn}_{2} \mathrm{GeO}_{4}$ was used as the working electrode. An Ag/AgCl electrode and a platinum electrode were used as the reference electrode and the counter electrode, respectively. Briefly, $5 \mathrm{mg}$ of the samples were dispersed into $2 \mathrm{~mL}$ ethanol and ultra-sonicated for $30 \mathrm{~min}$. Then, $10 \mu \mathrm{L}$ of the suspension was dropped onto the GCE and dried in air. The supporting electrolyte was the mixed solution of $\mathrm{KNO}_{3}\left(0.1 \mathrm{~mol} \mathrm{~L}^{-1}\right)$ and $5 \mathrm{mmol} \mathrm{L}^{-1} \mathrm{~K}_{3} \mathrm{Fe}(\mathrm{CN})_{5} / \mathrm{K}_{3} \mathrm{Fe}(\mathrm{CN})_{6}(1: 1)$. 


\section{Results and Discussion}

Fig. 1 shows the TEM images of the as-prepared nanostructured $\mathrm{Zn}_{2} \mathrm{GeO}_{4}$. When the crystal modifier is absent (Fig. 1a), the sample obtained is the short rods. And the length is about $100 \mathrm{~nm}$. When oleylamine $\left(0.1 \mathrm{~mol} \mathrm{~L}^{-1}\right)$ is introduced in the reaction system as a crystal modifier, the product is the mixture of long nanorods and short nanorods (Fig. 1b). The lengths are $100 \mathrm{~nm}$ and 500-800 nm, respectively. If the concentration of oleylamine increases to $0.16 \mathrm{~mol} \mathrm{~L}^{-1}$ (Fig. 1c), the product is basically long nanorods with the length of $500-800 \mathrm{~nm}$. In addition, when lactic acid serves as a crystal modifier, the length of nanorods decreases rather than increases. The length decreases from $100 \mathrm{~nm}$ to $50 \mathrm{~nm}$. And the change in the length can hardly be observed with the concentration increasing (Fig. 1d-e). However, we can find that both the high and low concentration of lactic acid make the size distribution of $\mathrm{Zn}_{2} \mathrm{GeO}_{4}$ nanomaterials become wider. Therefore, we believe that the morphology of $\mathrm{Zn}_{2} \mathrm{GeO}_{4}$ can be controlled through introduction of oleylamine or lactic acid.

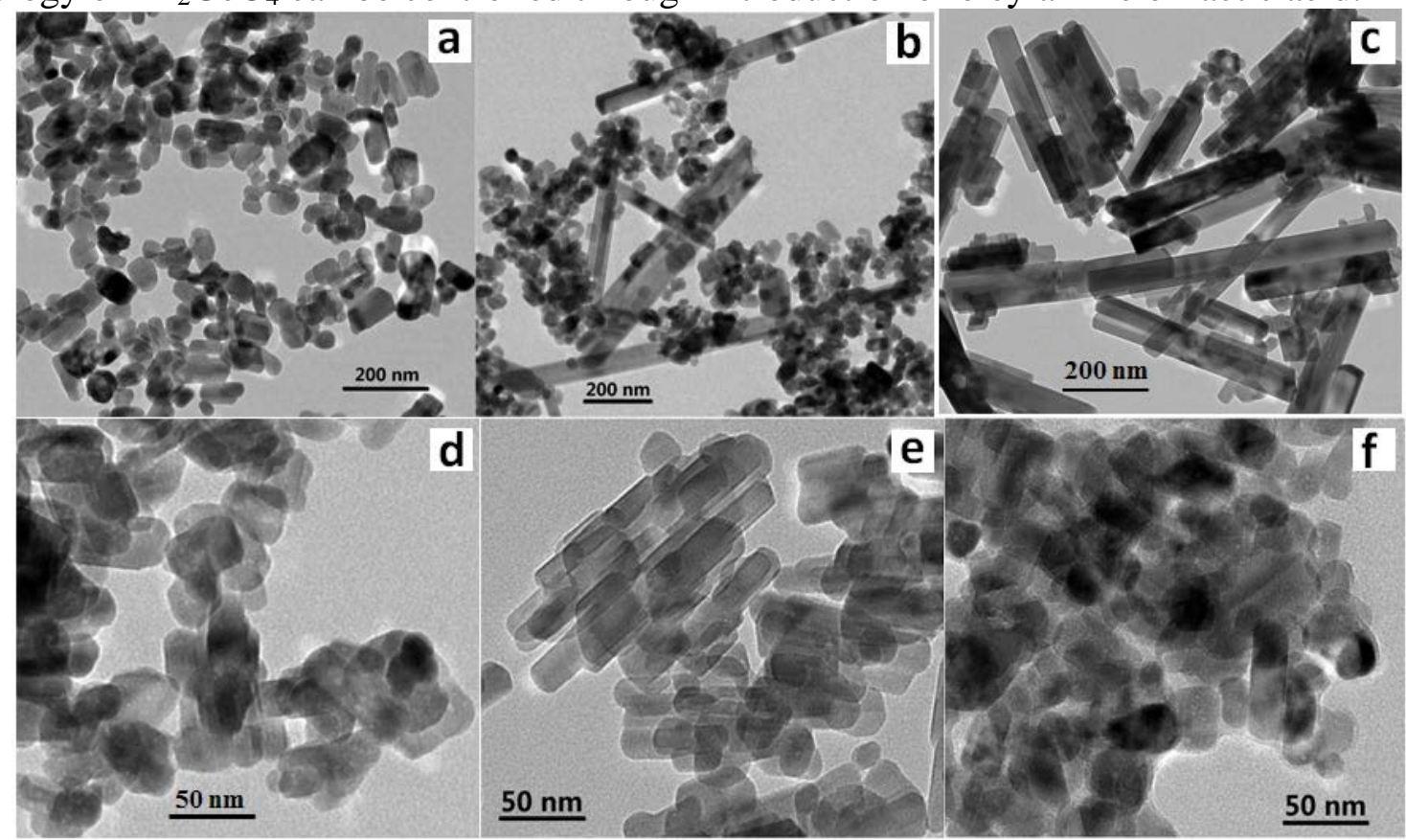

Fig.1. TEM images of $\mathrm{Zn}_{2} \mathrm{GeO}_{4}$ nanostructures prepared without crystal modifier (a) and with 0.1 mol L ${ }^{-1}$ oleylamine (b), $0.16 \mathrm{~mol} \mathrm{~L}^{-1}$ oleylamine (c), $0.16 \mathrm{~mol} \mathrm{~L}^{-1}$ lactic acid (d), $0.45 \mathrm{~mol} \mathrm{~L}^{-1}$ lactic acid (e) or $2.24 \mathrm{~mol} \mathrm{~L}^{-1}$ lactic acid (f).

Fig. 2 shows the XRD patterns of the as- prepared sample in the presence of oleylamine. We can see that when the $\mathrm{pH}$ was 8 (Fig. 2a) the XRD peaks of the resulting sample are narrow and sharp, indicating that the sample obtained possesses high crystallinity. In addition, compared with the JCPDS standard cards, the XRD patterns observed can match well with the JCPDS standard card (11-0687), indicating that the sample is hexagonal $\mathrm{Zn}_{2} \mathrm{GeO}_{4}$ nanorods with high purity. In order to explore the formation mechanism of $\mathrm{Zn}_{2} \mathrm{GeO}_{4}$ nanomaterials, we investigated the effect of $\mathrm{pH}$ on the phase of $\mathrm{Zn}_{2} \mathrm{GeO}_{4}$ nanomaterials. We can see that $\mathrm{Zn}_{2} \mathrm{GeO}_{4}$ can not be produced in the acidic environment (Fig. 2b). The XRD pattern of the product shows that the resulting product is $\mathrm{GeO}_{2}$. In contrast, we can easily obtain $\mathrm{Zn}_{2} \mathrm{GeO}_{4}$ nanorods with high purity and high crystallinity in alkaline environment (Fig. 2a). This may be due to that the $\mathrm{GeO}_{2}$ cannot be dissolved in acidic water, resulting in that the formation of $\mathrm{Zn}_{2} \mathrm{GeO}_{4}$ becomes by a heterogeneous reaction from homogeneous reaction. Therefore, the $\mathrm{Zn}_{2} \mathrm{GeO}_{4}$ generation speed is very slow so that little $\mathrm{Zn}_{2} \mathrm{GeO}_{4}$ is formed after 12 hours of reaction. In contrast, the alkaline environment would make the germanium acid monomer stable [9]. Based on the above results, we suggest that the formation mechanism of the $\mathrm{Zn}_{2} \mathrm{GeO}_{4}$ nanomaterials may be as follows: first, precursor $\mathrm{GeO}_{2}$ hydrolyzed to form $\mathrm{HGeO}^{3-}$. Then, $\mathrm{Zn}^{2+}$ and $\mathrm{HGeO}^{3-}$ reacted to form $\mathrm{Zn}_{2} \mathrm{GeO}_{4}$ seed. Next, the $\mathrm{Zn}_{2} \mathrm{GeO}_{4}$ crystals grow gradually to form $\mathrm{Zn}_{2} \mathrm{GeO}_{4}$ nanorods. 


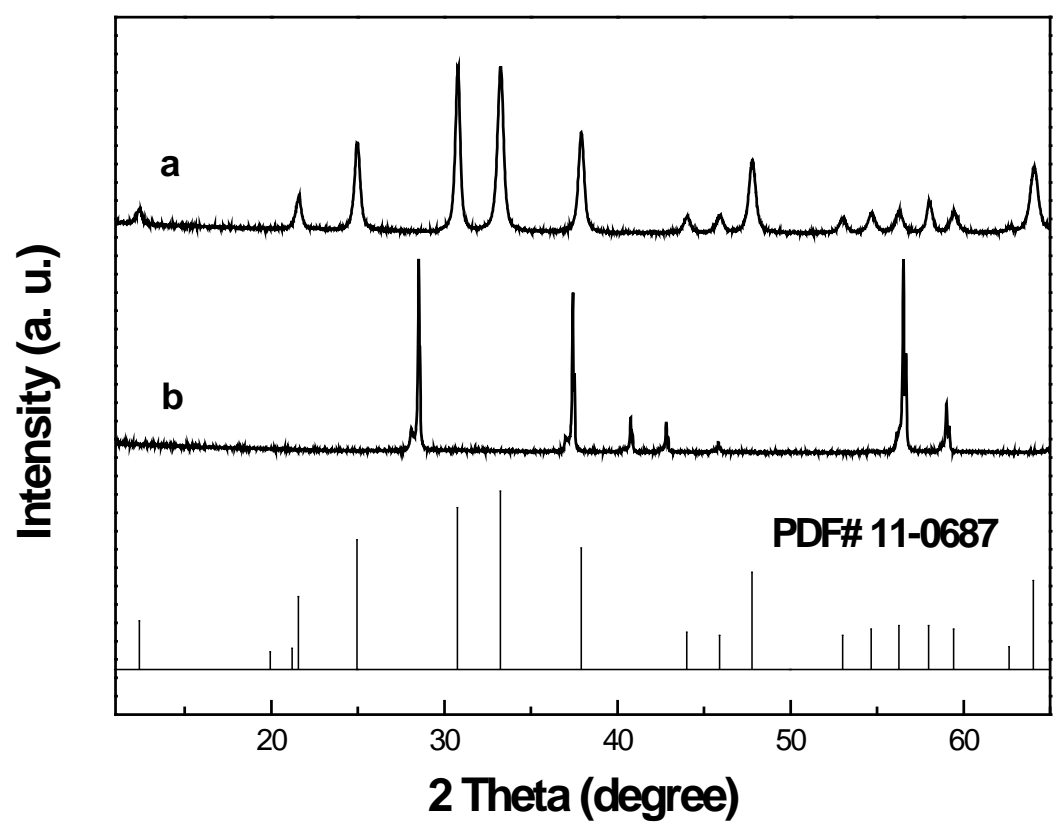

Fig.2. XRD patterns of products prepared with $0.16 \mathrm{~mol} \mathrm{~L}^{-1}$ oleylamine at $\mathrm{pH}=8$ (a) and 1 (b).

Fig. 3 (A) shows the cyclic voltammograms of $\mathrm{Zn}_{2} \mathrm{GeO}_{4}$ nanomaterials at various potential scan rates. Meanwhile, the corresponding calibration plots of oxidation and reduction peak currents as a function of scan rate's root are also shown in Fig. 3. It indicates that both oxidation peak currents and reduction peak currents increase linearly with the scan rate's root. The corresponding linear equations are $\mathrm{y}=0.01953+0.00491 \mathrm{x}$ and $\mathrm{y}=-0.00594 \mathrm{x}-0.01459$, respectively. The linear correlation coefficients are 0.991 and 0.998 . It indicates that the oxidation process of $\mathrm{Fe}^{2+}$ and reduction process of $\mathrm{Fe}^{3+}$ on the $\mathrm{Zn}_{2} \mathrm{GeO}_{4}$ nanomaterials modified electrodes are diffusion controlled processes.

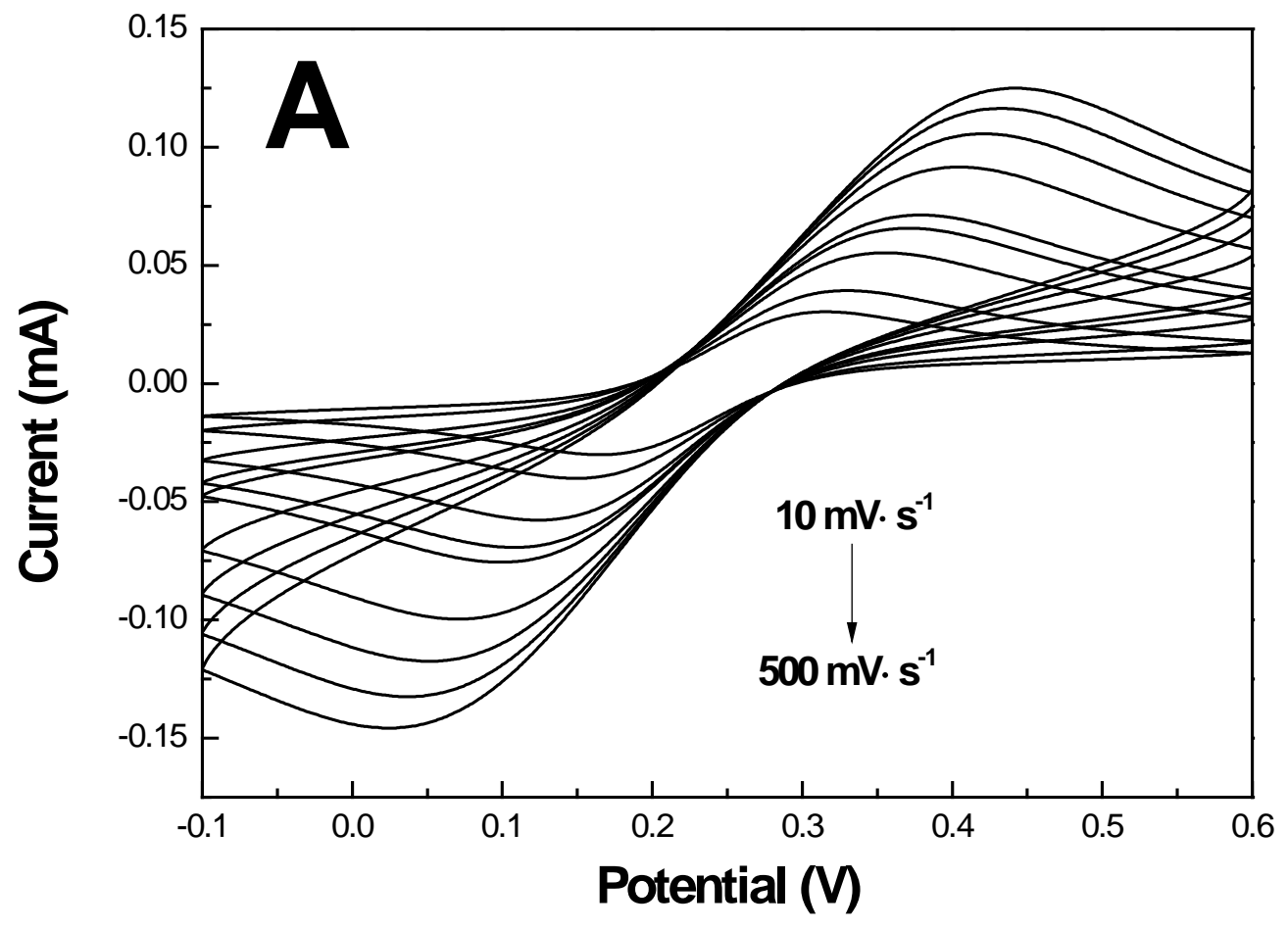




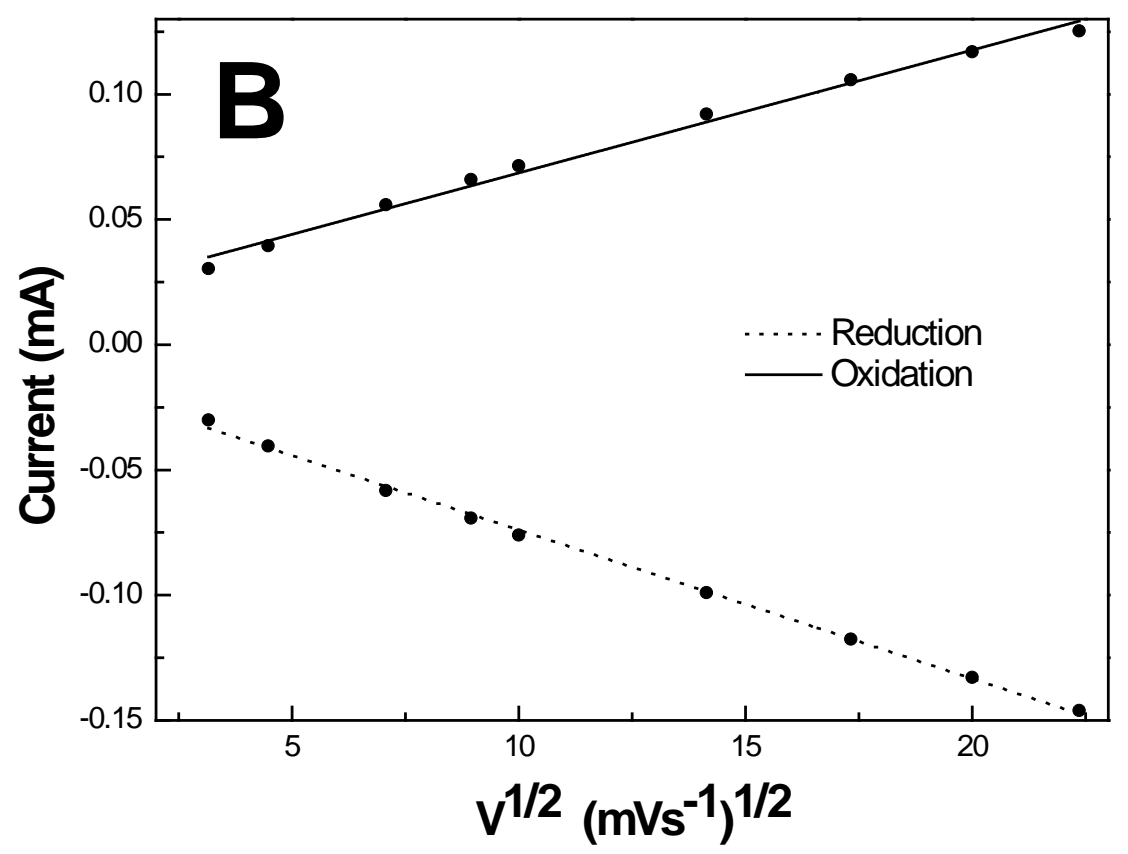

Fig.3. (A) Cyclic voltammograms of $\mathrm{Zn}_{2} \mathrm{GeO}_{4}$ nanomaterials prepared with $0.16 \mathrm{~mol} \mathrm{~L}^{-1}$ oleylamine at different potential scan rate. (B) The corresponding calibration plots of oxidation and reduction peak currents as a function of scan rate's root.

Fig. 4 shows the EIS curves of the $\mathrm{Zn}_{2} \mathrm{GeO}_{4}$ nanomaterials with various lengths. We can see that the semicircle diameters of the $\mathrm{Zn}_{2} \mathrm{GeO}_{4}$ nanomaterial with $50 \mathrm{~nm}$ (Fig. 4a), $100 \mathrm{~nm}$ (Fig. 4b), and 500-800 nm (Fig. 4c) are $2300 \Omega, 1500 \Omega$, and $1200 \Omega$, respectively. It can be found that with the increase of the length of $\mathrm{Zn}_{2} \mathrm{GeO}_{4}$ nanomaterial, the semicircle diameters of the $\mathrm{Zn}_{2} \mathrm{GeO}_{4}$ nanomaterial were gradually decreased. The electron transfer resistance of the electrode is equal to the semicircle diameter of EIS and can be used to evaluate the interface properties of the electrodes. We can see that longer the length is, smaller the electron transfer resistance is. So, it can be deduced that the long $\mathrm{Zn}_{2} \mathrm{GeO}_{4}$ nanorods possesses better electron transport property in comparison with the short $\mathrm{Zn}_{2} \mathrm{GeO}_{4}$ nanorods.

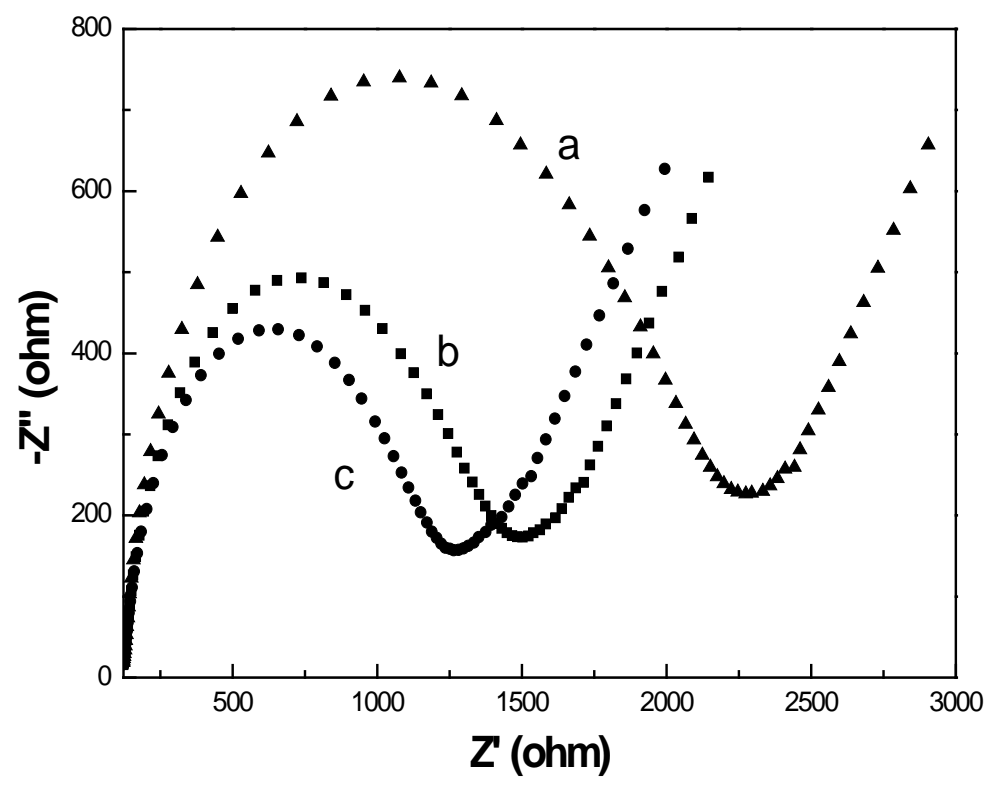

Fig.4. EIS of $\mathrm{Zn}_{2} \mathrm{GeO}_{4}$ nanomaterials with different lengths: $50 \mathrm{~nm}$ (a), $100 \mathrm{~nm}$ (b), and 500-800 $\mathrm{nm}(\mathrm{c})$ 


\section{Summary}

In summary, we have successfully control the morphology of the $\mathrm{Zn}_{2} \mathrm{GeO}_{4}$ nanomaterials through tuning the kind and concentration of crystal modifiers. In addition, we also found that $\mathrm{pH}$ is one of the key factors for preparation of $\mathrm{Zn}_{2} \mathrm{GeO}_{4}$ nanomaterials under hydrothermal conditions. Finally, the long length of $\mathrm{Zn}_{2} \mathrm{GeO}_{4}$ nanomaterials is favorable to the electron transfer.

\section{Acknowledgement}

This work was financially supported by the National Natural Science Foundation of China (No. 21301118).

\section{References}

[1] L. Z. Pei, J. F. Wang, L. J. Yang, Y. P. Dong, S. B. Wang, C. G. Fan, J. L. Hu, Q. F. Zhang, Cryst. Res. Technol. 46 (2011) 103-112.

[2] Q. Liu, Y. Zhou, W. Tu, S. Yan, Z. Zou, Inorg. Chem. 53 (2014) 359-364.

[3] L. Li, P. S. Lee, C. Yan, T. Zhai, X. Fang, M. Liao, Y. Koide, Y. Bando, D. Golberg, Adv. Mater. 22 (2010) 5145-5149.

[4] R. Wang, S. Wu, Y. Lv, Z. Lin, Langmuir. 30 (2014) 8215-8220.

[5] J. Feng, M. O. Lai, L. Lu, 47 (2012) 1693-1696.

[6] W. Zhao, C. Zhang, Y. Shi, R. Wu, B. Zhang, Dalton Trans. 44 (2015) 75-82.

[7] S. Mourdikoudis, L. M. Lizmarzán, Chem. Mater. 25 (2013) 1465-1476.

[8] D. Jia, Z. Zhang, G. Yao, Z. Huo, F. Jin, Catal. Today. 263(2016) 112-116.

[9] V. B. R. Boppana, N. D. Hould, R. F. Lobo, J. Solid State Chem. 184 (2011) 1054-1062. 